\title{
Lateral flow test strip based on colloidal selenium immunoassay for rapid detection of melamine in milk, milk powder, and animal feed
}

This article was published in the following Dove Press journal:

International Journal of Nanomedicine

3 April 2014

Number of times this article has been viewed

\author{
Zhizeng Wang' \\ Dejuan Zhi ${ }^{2}$ \\ Yang Zhao' \\ Hailong Zhang ${ }^{2}$ \\ Xin Wang ${ }^{2}$ \\ Yi Ru' \\ Hongyu $\mathrm{Li}^{1,2}$ \\ 'MOE Key Laboratory of Cell \\ Activities and Stress Adaptations, \\ School of Life Sciences, Lanzhou \\ University, Lanzhou, People's Republic \\ of China; ${ }^{2}$ Institute of Microbiology \\ and Biochemical Pharmacy, School of \\ Pharmaceutics, Lanzhou University, \\ Lanzhou, People's Republic of China
}

\begin{abstract}
Although high melamine (MEL) intake has been proven to cause serious health problems, MEL is sometimes illegally added to milk products and animal feed, arousing serious food safety concerns. A satisfactory method of detecting MEL in onsite or in-home testing is in urgent need of development. This work aimed to explore a rapid, convenient, and cost-effective method of identifying MEL in milk products or other food by colloidal selenium-based lateral flow immunoassay. Colloidal selenium was synthesized by L-ascorbic acid to reduce seleninic acid at room temperature. After conjugation with a monoclonal antibody anti-MEL, a test strip was successfully prepared. The detection limit of the test strip reached $150 \mu \mathrm{g} / \mathrm{kg}, 1,000 \mu \mathrm{g} / \mathrm{kg}$, and $800 \mu \mathrm{g} / \mathrm{kg}$ in liquid milk, milk powder, and animal feed, respectively. No cross-reactions with homologues cyanuric acid, cyanurodiamide, or ammelide were found. Moreover, the MEL test strip can remain stable after storage for 1 year at room temperature. Our results demonstrate that the colloidal selenium MEL test strip can detect MEL in adulterated milk products or animal feed conveniently, rapidly, and sensitively. In contrast with a colloidal gold MEL test strip, the colloidal selenium MEL test strip was easy to prepare and more cost-efficient.
\end{abstract}

Keywords: melamine, selenium nanoparticles, test strip, milk, animal feed, dairy food

\section{Introduction}

Melamine (MEL) is a typical polar organic triazine compound with the chemical formula $\mathrm{C}_{3} \mathrm{H}_{6} \mathrm{~N}_{6}$ that is usually used as an industrial chemical. ${ }^{1,2}$ There have been several events of MEL being criminally added to milk, milk powder, and other food products in order to artificially elevate the apparent crude protein content by means of its high nitrogen content of $66.7 \% .^{3}$ Excess MEL intake has led to serious health problems. ${ }^{4-9}$ It has been reported that poisonous pet food resulting from deliberate MEL contamination severely impacted the health of thousands of dogs and cats between 2004 and 2007 in the USA. ${ }^{10}$ Poisonous milk powder released in 2008 affected over 294,000 children and infants, of whom approximately 54,000 were hospitalized and six died in the People's Republic of China. ${ }^{11,12}$ Similar cases have been reported in Vietnam and Singapore. ${ }^{12}$ MEL-contaminated infant food was also found in 2008 in the USA, ${ }^{12} 2010$ in the People's Republic of China, ${ }^{13}$ and again in 2013 in the USA. ${ }^{14}$ Although the maximum permitted concentration of MEL has been set at $2.5 \mathrm{mg} / \mathrm{kg}$ for both adult food and animal feed and $1.0 \mathrm{mg} / \mathrm{kg}$ for infant food by the World Health Organization, ${ }^{11,15,16}$ illegally contaminated milk products and animal feed are still occasionally found. Because of the serious food safety concerns, there is an urgent need to explore a rapid, sensitive, and inexpensive detection method by which to determine
Correspondence: Hongyu $\mathrm{Li}$ MOE Key Laboratory of Cell Activities and Stress Adaptations, School of Life Sciences, Lanzhou University, Tianshui Road No 222, Lanzhou, 730000, People's Republic of China

Tel +869318915686

Fax +869318915686

Email lihy@|zu.edu.cn 
the likelihood of MEL contamination of milk products or animal feeds, especially for onsite and in-home testing.

Although methods have been utilized to detect MEL, not all of these are satisfactory. For example, high-performance liquid chromatography alone ${ }^{17-19}$ or combined with tandem mass spectrometry (MS/MS), ${ }^{18-20}$ gas chromatographymass spectrometry, ${ }^{21}$ capillary electrophoresis, ${ }^{22}$ infrared spectroscopy, ${ }^{23,24}$ and nuclear magnetic resonance spectroscopy ${ }^{25}$ are highly sensitive but require complicated pretreatment procedures and expensive instruments and equipment. Moreover, most of these tests require large amounts of organic solvents that are dangerous to user health and harmful to the environment. ${ }^{24}$

The colorimetric method based on colloidal gold ${ }^{3}$ has been reported recently. Although it is simple, rapid, and economical, some samples still require complicated pretreatment. An alternative method of competitive enzyme-linked immunosorbent assay ${ }^{26}$ avoids the complex pretreatment, but needs to be operated by a trained professional. All of these MEL detection methods do not meet the requirements for onsite and in-home testing.

The only MEL detection device currently available for onsite and in-home testing is a one-step, colloidal goldbased test strip. ${ }^{27-29}$ Colloidal gold particles are costly, ${ }^{30,31}$ and the preparation process for colloidal gold is relatively complicated. Considering the drawbacks of current methods for MEL detection, the aims of this study were to employ colloidal selenium particles for binding to antibodies against MEL and prepare a lateral flow test strip based on colloidal selenium immunoassay. The test strip can be prepared simply. Furthermore, it can be used conveniently, rapidly, specifically, in regards to detection substance sensitively, and cost-effectively.

\section{Materials and methods}

The following materials were acquired: MEL (Lot 08002; National Institute of Metrology, Beijing, People's Republic of China); bovine serum albumin (BSA) (Sigma-Aldrich, St Louis, MO, USA); BSA-MEL conjugant (Guangzhou Ebiogenes Biotech Ltd, Guangzhou, People's Republic of China); anti-MEL monoclonal antibody (McAb) (Guangzhou Ebiogenes Biotech Ltd); Tween 20 (Promega Corporation, Fitchburg, WI, USA); L-ascorbic acid (Sigma-Aldrich); seleninic acid $\left(\mathrm{H}_{2} \mathrm{SeO}_{3}\right)$ (Tianjin Tianhe Chemical Reagent Factory, Tianjin, People's Republic of China); gum arabic (GA), (Tianjin Bodi Chemical Co, Ltd, Tianjin, People's Republic of China); goat anti-mouse immunoglobulin $\mathrm{G}$ (IgG) (Shanghai Jieyi Biotechnology Co, Ltd, Shanghai,
People's Republic of China); nitrocellulose membrane (NCM) (Merk Millipore, Billerica, MA, USA); glass fiber (SB08; Shanghai Jieyi Biotechnology Co, Ltd); liquid milk (Lanzhou Manor Pasture Co, Ltd, Lanzhou, People's Republic of China); milk powder (Abbott Laboratories, Abbott Park, IL, USA); and animal feed (Tianjin Guayuelvfa Food Co, Ltd, Tianjin, People's Republic of China).

\section{Preparation of colloidal selenium particles}

Colloidal selenium particles were synthesized by reducing $\mathrm{H}_{2} \mathrm{SeO}_{3}$ with L-ascorbic acid, and GA powder was used as a stabilizing agent. ${ }^{32,33}$ Briefly, $10 \mathrm{~mL}$ of $2.5 \%$ weight/volume (w/v) GA powder was added to $88 \mathrm{~mL}$ of deionized water with continuous stirring for 5 minutes at room temperature (RT), then $1 \mathrm{~mL}$ of $0.8 \mathrm{M} \mathrm{L}$-ascorbic acid and $1 \mathrm{~mL}$ of 0.2 $\mathrm{M} \mathrm{H}_{2} \mathrm{SeO}_{3}$ were added with stirring for another 10 minutes to allow the reaction to complete. The colloidal selenium particles were characterized by transmission electron microscopy (TEM). ${ }^{34,35}$

\section{Preparation of colloidal selenium particle-conjugated McAb anti-MEL}

The $\mathrm{pH}$ of colloidal selenium was adjusted to 8.3 with $0.1 \mathrm{M}$ $\mathrm{K}_{2} \mathrm{CO}_{3}$ (potassium carbonate). Then, $50 \mu \mathrm{L}$ of $1 \mathrm{mg} / \mathrm{mL}$ antiMEL McAb was added in drops to $10 \mathrm{~mL}$ colloidal selenium solution with gentle stirring at RT. After the mixture was softly agitated for 10 minutes, antibodies were conjugated to colloidal selenium particle surfaces by physical adsorption. Ten percent $(\mathrm{w} / \mathrm{v}) \mathrm{BSA}$ solution $(1.1 \mathrm{~mL})$ was added to the mixture to block the non-coated colloidal selenium particle surfaces for 10 minutes, and then the mixture was centrifuged at 10,000 rpm for 25 minutes. Colloidal selenium particleconjugated anti-MEL McAb in soft pellet form was collected after being washed twice by centrifugation at 10,000 rpm for 25 minutes. Finally, colloidal selenium particle-conjugated anti-MEL McAb was resuspended in $2 \mathrm{~mL}$ dilution buffer (10 mM Tris hydrochloride, containing 1\% [w/v] BSA, $0.2 \%$ Tween 20,0.05\% [w/v] polyvinylpyrrolidone, and 5\% [w/v] sucrose), ${ }^{36-38}$ and then stored at $4^{\circ} \mathrm{C}$ before use..$^{39,40}$

\section{Preparation of MEL test strips}

The preparation and assemblage of the immunoassay test device is shown in Figure 1A. ${ }^{37}$ Briefly, goat anti-mouse IgG and BSA-MEL were separately applied to NCM $(2.5 \times 2.0 \mathrm{~cm})$ with $3.5 \mu \mathrm{g}$ in $10 \mathrm{mM}$ phosphate-buffered saline, $\mathrm{pH} 7.4$, to be used as the control zone and the test zone. The distance between the control zone and the test zone was 
A

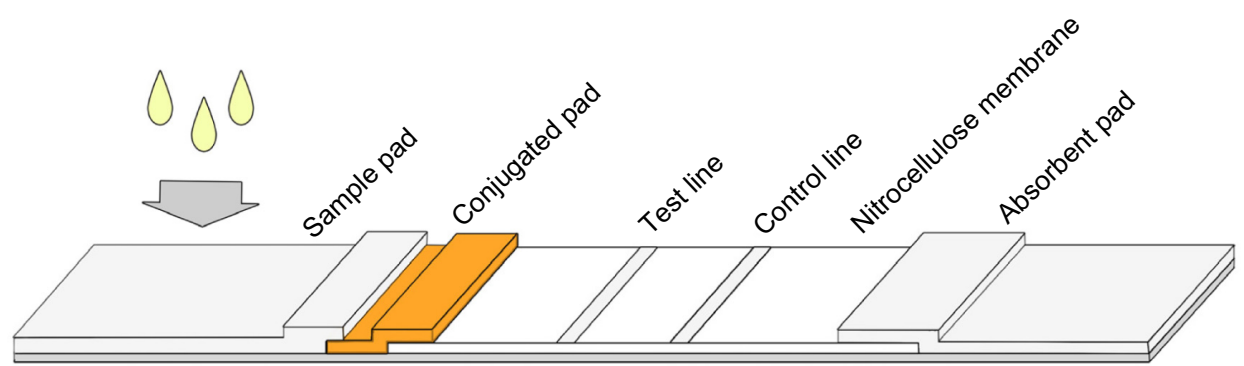

Flow direction

\section{B}
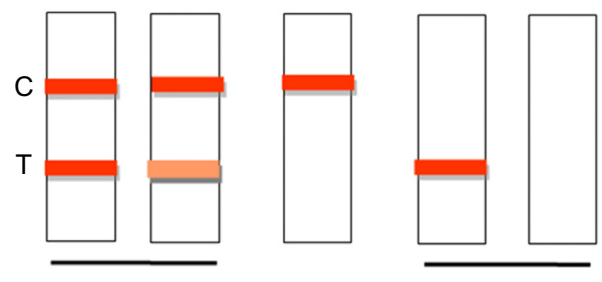

Positive

Invalid

Figure I Schematic diagram of the immunochromatographic melamine test strip.

Notes: (A) The preparation and assembly of the immunoassay melamine test strip. (B) Result judgment of the test strip. C, control line; T, test line.

$0.5 \mathrm{~cm}$. The NCM was then dried for 1.5 hours at $37^{\circ} \mathrm{C}$ to fix the antibody and antigen. The NCM was pasted onto the polyvinyl chloride strip with the adsorption pad on the top end, and the colloidal selenium-conjugated pad overlapped by the sample pad was adhered to the bottom end of the NCM. The colloidal selenium-conjugated pad had been prepared by adding the anti-MEL McAb-coated colloidal selenium nanoparticles (SeNPs) to the SB08 glass fiber $(2.5 \times 1.0 \mathrm{~cm})$. The resultant conjugated pad was incubated at $37^{\circ} \mathrm{C}$ for 1.5 hours until fully dried. The sample pad of SB08 glass fiber $(2.5 \times 2.0 \mathrm{~cm})$ was submerged in $10 \mathrm{mM}$ phosphatebuffered saline, $\mathrm{pH} 7.4$ and containing $0.05 \%$ Tween 20 , and dried at $37^{\circ} \mathrm{C}$ for 1.5 hours. Finally, the test device was cut into $5 \mathrm{~mm}$-wide strips and stored at RT before use. ${ }^{36}$

\section{Determination of the sensitivity and cross-reactivity of MEL test strips}

Liquid milk samples were diluted threefold in deionized water, then added standard MEL at concentrations of 0,1 , $5,10,50,100$, and $500 \mu \mathrm{g} / \mathrm{L}$. One gram of milk powder was added to $20 \mathrm{~mL}$ deionized water, and spiked standard MEL at concentrations of $0,1,5,10,50,100$, and $500 \mu \mathrm{g} / \mathrm{L}$. One gram of animal feed was finely ground, then added to $8 \mathrm{~mL}$ deionized water, and spiked standard MEL at concentrations of $0,1,5,10,50,100$, and $500 \mu \mathrm{g} / \mathrm{L}$, mixed completely, and stored at RT for 30 minutes before use. Next, $100 \mu \mathrm{L}$ samples containing liquid milk, milk powder, and animal feed were tested by MEL test strips in triplicate. ${ }^{28}$

The concentrations of MEL in uncontaminated samples were all testified by the liquid chromatography (LC)-MS/MS method. The limit of detection (LOD) for MEL test strips in milk products was also validated by LC-MS/MS according to previous work by Goscinny et al. ${ }^{18}$

Five hundred micrograms per liter cyanuric acid, $500 \mu \mathrm{g} / \mathrm{L}$ ammelide, and $500 \mu \mathrm{g} / \mathrm{L}$ cyanurodiamide were added to different samples of liquid milk diluted threefold in deionized water, then $100 \mu \mathrm{L}$ of each sample was introduced on the strip sample region for cross-reactivity assay. ${ }^{37,41}$

The results could be observed by the naked eye within 5 minutes. A schematic representation of the immunochromatographic test strip is shown in Figure $1 \mathrm{~B}$. The test lineimmobilized BSA-MEL can react with anti-MEL McAb, thus capturing adequate colloidal selenium particles to show an orange test line. If there is elevated MEL in the tested sample, the MEL will react with anti-MEL McAb first, leaving insufficient anti-MEL McAb for BSA-MEL to bind to, hence no visible test line can be observed due to lack of colloidal selenium particles. The intensity of the test line color is proportionate to the quantity of MEL in the sample. Similarly, the immobilized goat anti-mouse IgG in the control area will always react with anti-MEL McAb to show an orange line. The positive result is determined by the appearance of 
an orange line in the control area, but the absence of it in the test area. The negative result is determined by an orange line exhibited in both the test area and the control area. If no visible orange line is present in the control area, the test strip is considered invalid regardless of whether an orange line appears in the test area or not. ${ }^{37}$

\section{Evaluation of the stability of MEL test strips}

The prepared test strip was stored in a desiccator for 1 year, then used to detect different concentrations of MEL in matrix samples as sensitivity assay in triplicate..$^{37,42}$

\section{Results}

\section{Characterization of the colloidal selenium}

Colloidal selenium was synthesized by L-ascorbic acid reduction. During the process of selenium particle preparation, the suspension changed from colorless to transparent orange (Figure 2). As with the preparation of colloidal gold, ${ }^{43}$ gold ions are reduced to gold atoms in solution; in turn, gold atoms immediately aggregate to form gold cores, then gold atoms continuously bind to those gold cores. Finally, gold nanoparticles are achieved. SeNPs are formed similarly, and it is difficult to assay how many selenium atoms on a diameter on picometer level form an SeNP. In our experiment, SeNPs were evaluated under TEM (Figure 3). Our results showed that SeNPs were spherical, with an average diameter of $57.97 \pm 6.84 \mathrm{~nm}$. No colloidal selenium particle agglomeration was found, suggesting that

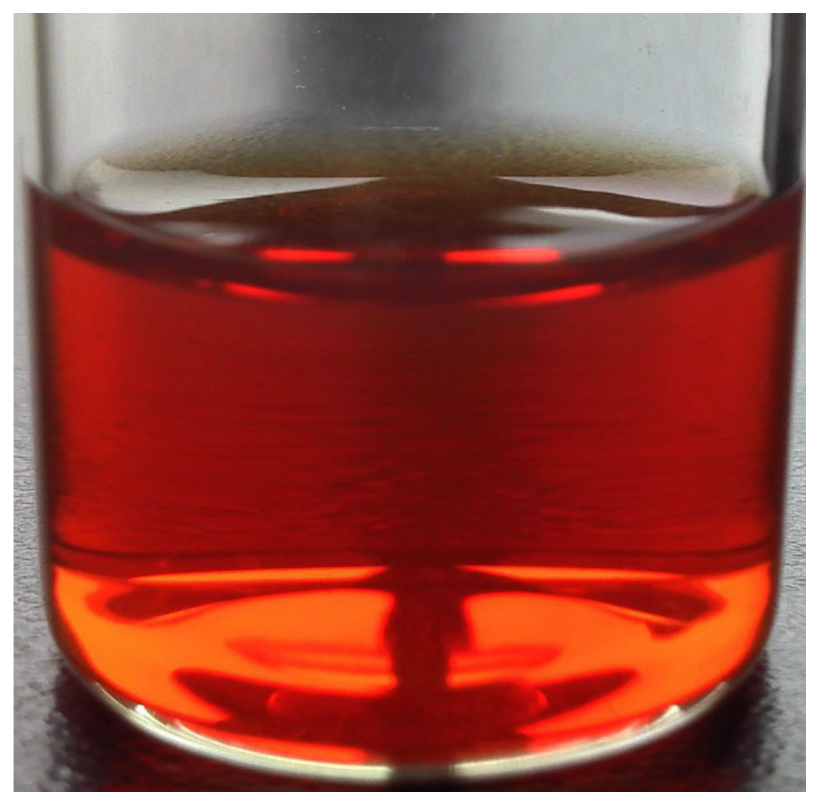

Figure 2 The colloidal selenium as it appears to the naked eye.
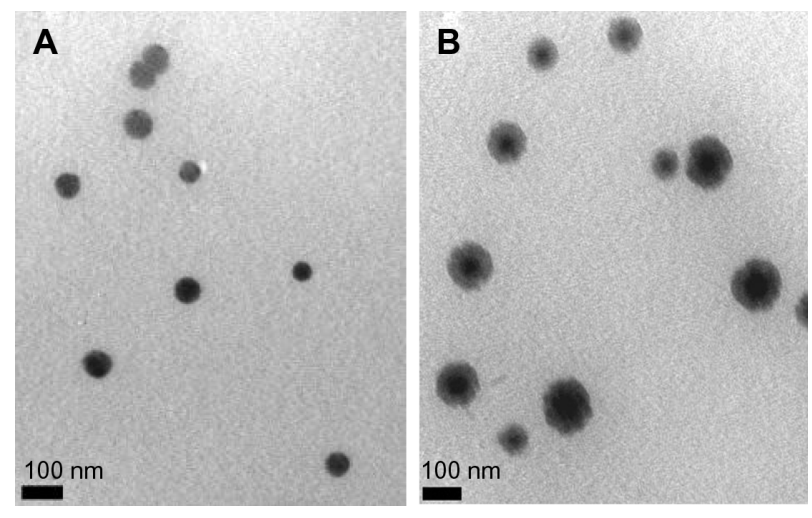

Figure 3 The labeling results of colloidal selenium probe were characterized by transmission electron microscopy (TEM).

Notes: (A) Selenium nanoparticles. (B) Labeled selenium nanoparticles (showing the protein halo around the labeled particles).

GA can keep the colloidal selenium particles stable. Such SeNPs can be resuspended completely, thus meeting the needs of colloidal selenium for probes. After conjugation with antibodies against MEL, the colloidal SeNPs were surrounded evenly by the antibody proteins. The morphological character of antibody-labeled SeNPs was identified with that of colloidal gold particles conjugated by antibodies under TEM in previous work. ${ }^{39}$

\section{Sensitivity of MEL test strips in liquid milk, milk powder, and animal feed}

Preliminary concentrations of MEL in liquid milk, milk powder, and animal feed were analyzed by LC-MS/MS, and the results showed that they contained MEL at levels of $11.4 \mu \mathrm{g} / \mathrm{kg}, 23.6 \mu \mathrm{g} / \mathrm{kg}$, and $1.15 \mu \mathrm{g} / \mathrm{kg}$, respectively. Liquid milk, milk powder, and animal feed were spiked with different concentrations of standard MEL, which was then detected by the MEL test strip. Finally, the LOD of MEL in liquid milk, milk powder, and animal feed was determined at 50 $\mu \mathrm{g} / \mathrm{L}$ (Figure 4), $50 \mu \mathrm{g} / \mathrm{L}$ (Figure 5), and $100 \mu \mathrm{g} / \mathrm{L}$ (Figure $6)$, respectively. All the results were repeated in triplicate throughout our experiment. The intensity of the orange test line decreased in proportion to the concentration of MEL in samples from $1 \mu \mathrm{g} / \mathrm{L}$ to $50 \mu \mathrm{g} / \mathrm{L}$. False positive results were not obtained in any of the tests.

\section{Cross-reactivity of MEL test strips}

The cross-reactivity of cyanuric acid, ammelide, and cyanurodiamide on the MEL strips was assayed in triplicate. The results showed that only $500 \mu \mathrm{g} / \mathrm{L}$ of MEL produced a positive result. Negative results were obtained for cyanuric acid, ammelide, and cyanurodiamide (Figure 7), indicating clear specificity of the MEL test strips. 


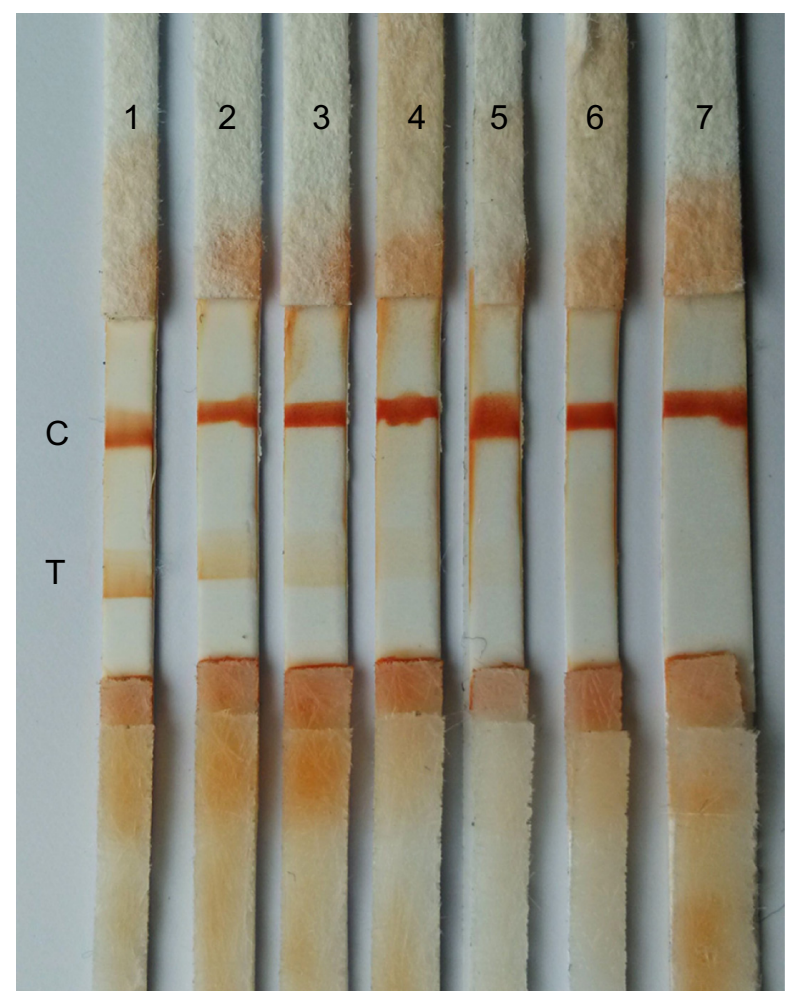

Figure 4 The sensitivity of melamine test strips in liquid milk.

Notes: I: uncontaminated milk; 2-7: uncontaminated milk spiked with melamine at concentrations of I, 5, 10,50, 100, and $500 \mu \mathrm{g} / \mathrm{L}$, respectively.

Abbreviations: $\mathrm{C}$, control line; $\mathrm{T}$, test line.

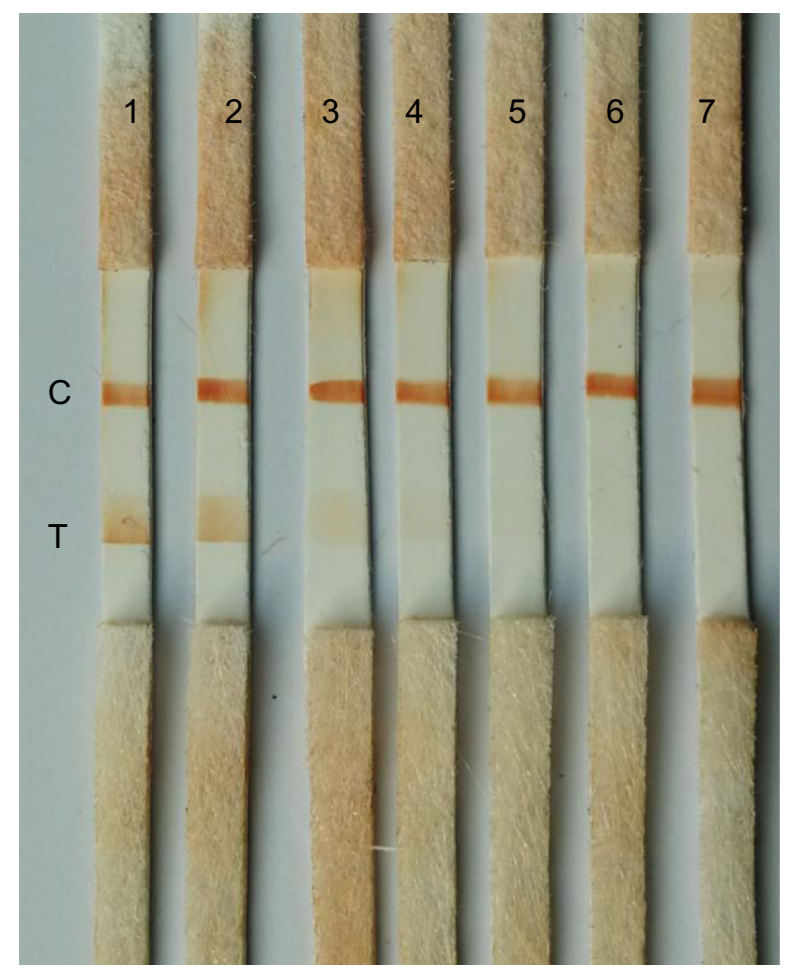

Figure $\mathbf{5}$ The sensitivity of melamine test strips in milk powder.

Notes: I: uncontaminated milk powder; 2-7: uncontaminated milk powder spiked with melamine at concentrations of I, 5, 10, 50, 100, and $500 \mu \mathrm{g} / \mathrm{L}$, respectively. Abbreviations: $\mathrm{C}$, control line; $\mathrm{T}$, test line.

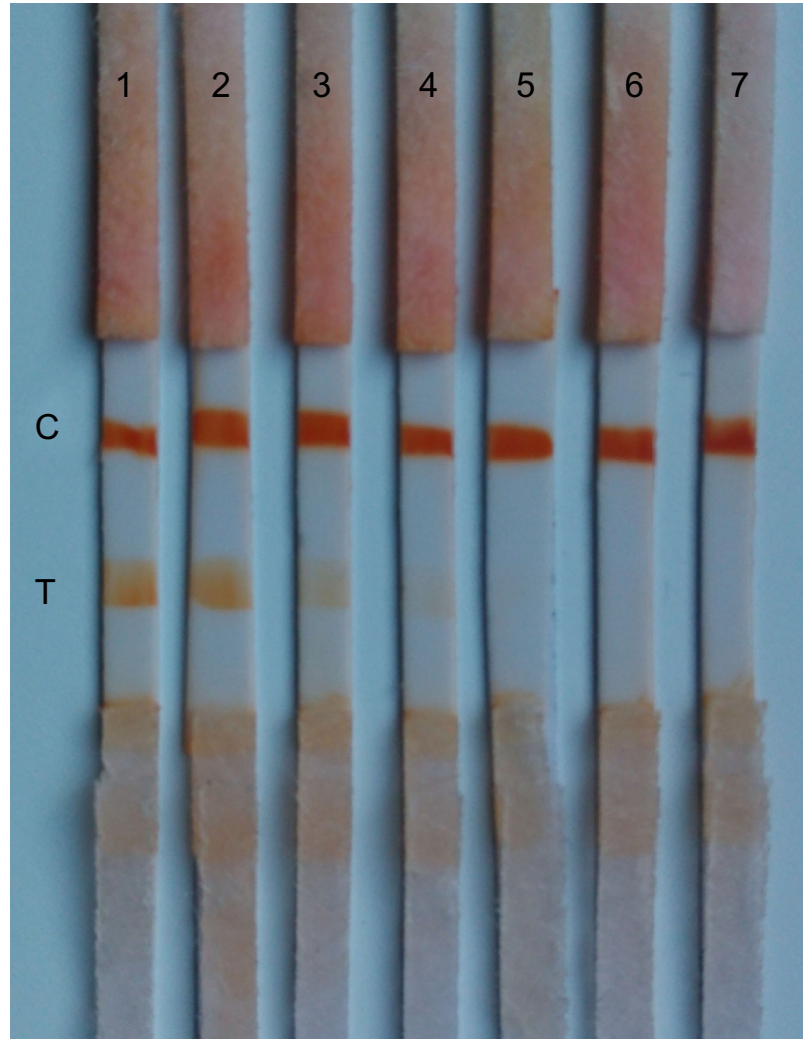

Figure 6 The sensitivity of melamine test strips in animal feed. Notes: I: uncontaminated animal feed; 2-7: uncontaminated animal feed spiked with melamine at concentrations of $10,20,50,100,200$, and $500 \mu \mathrm{g} / \mathrm{L}$, respectively. Abbreviations: $\mathrm{C}$, control line; $\mathrm{T}$, test line.

\section{Stability of MEL test strips}

After MEL test strips were stored in a dry and dark environment for 1 year, they were used for stability analysis. All analyses were completed within 5 minutes. The LODs of the MEL test strips were $50 \mu \mathrm{g} / \mathrm{L}$ in milk products and $100 \mu \mathrm{g} / \mathrm{L}$ in animal feed, respectively (Figures 8-10), identical to the previous tests. No false positive results were found in any of the tests.

\section{Discussion}

In this study, appropriate colloidal selenium particles were successfully prepared by using L-ascorbic acid as a reducing agent and GA powder as a stabilizing agent. The colloidal selenium was observed to be transparent and orange in color. Those particles were characterized in spherical form and uniformly dispersed, easily resuspended after centrifugation, shown to be completely coated by protein of anti-MEL McAb under TEM in different batches, and stable after storage for 3 months at RT.

Nanoparticle morphology influencing the color signal of the test strip has been reported in a previous 


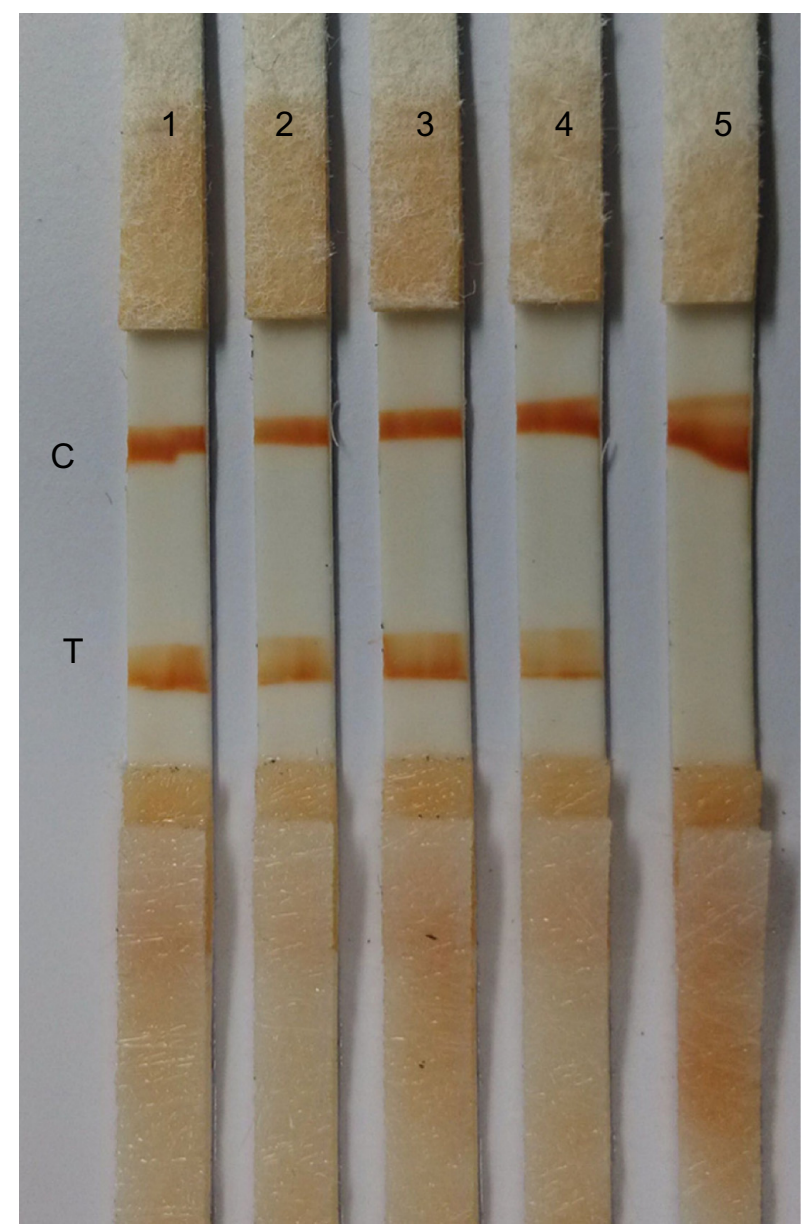

Figure 7 The cross-reactivity test of melamine test strips.

Notes: I: uncontaminated milk; 2: $500 \mu \mathrm{g} / \mathrm{L}$ cyanuric acid in milk; 3: $500 \mu \mathrm{g} / \mathrm{L}$ ammelide in milk; 4: $500 \mu \mathrm{g} / \mathrm{L}$ cyanurodiamide in milk; $5: 500 \mu \mathrm{g} / \mathrm{L}$ melamine in milk. Abbreviations: $\mathrm{C}$, control line; $\mathrm{T}$, test line.

investigations study, ${ }^{43}$ however, it was not found in the present work. Different concentrations of GA were added as a stabilizing agent to prepare the colloidal selenium, then the SeNPs were also assayed by TEM. The results showed that the shape of SeNPs was always spherical, but that size decreased with the concentration of GA. GA at $0.25 \%$ concentration was finally chosen due to its resulting in relatively uniform SeNPs with excellent stability and potential for resuspension. Such SeNPs could readily lead to a good color signal on the test strips. During our primary experiment, it was found that the ratio of antibodies to SeNPs affected the detecting result. When SeNPs were conjugated with $0.1 \mu \mathrm{g}$ or $1 \mu \mathrm{g}$ antibodies, a very weak control line and test line resulted, thus causing an equivocal result. When $5 \mu \mathrm{g}$ and $10 \mu \mathrm{g}$ antibodies were used, a satisfactory result was obtained and the sensitivity and color intensity of the test strip showed no obvious difference. Therefore, the ratio of $5 \mu \mathrm{g}$ antibody per $1 \mathrm{~mL}$ colloidal selenium was used throughout our experiment.

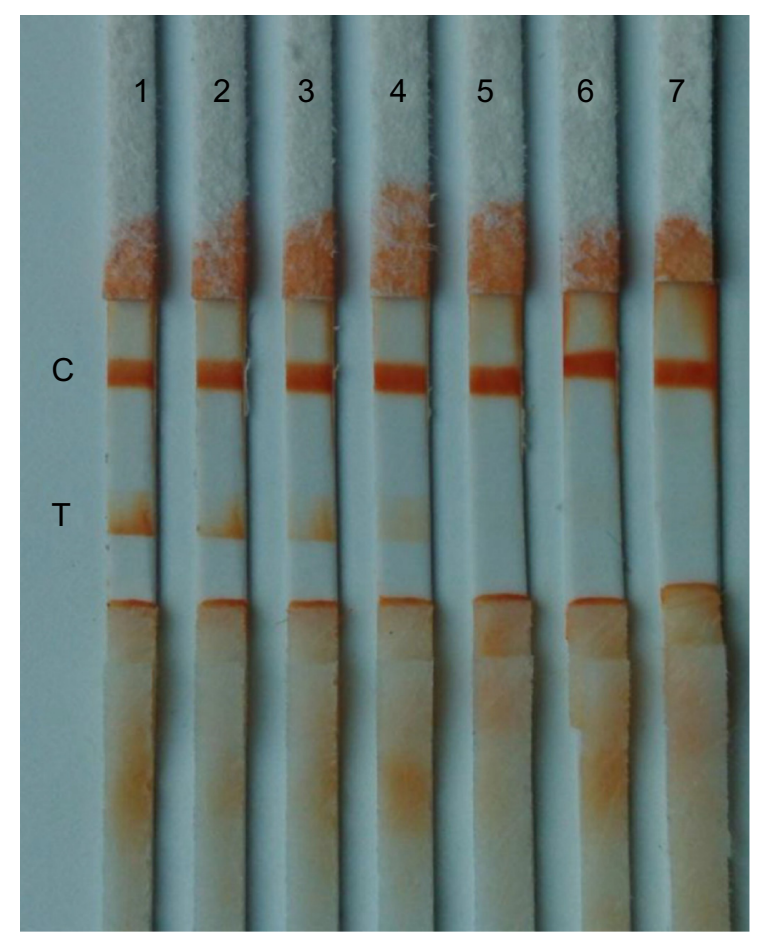

Figure 8 The stability assay of melamine test strips after storage in a dry and dark environment for I year.

Notes: I: uncontaminated milk; 2-7: uncontaminated milk spiked with melamine at concentrations of $\mathrm{I}, 5,10,50,100$, and $500 \mu \mathrm{g} / \mathrm{L}$, respectively.

Abbreviations: $\mathrm{C}$, control line; $\mathrm{T}$, test line.

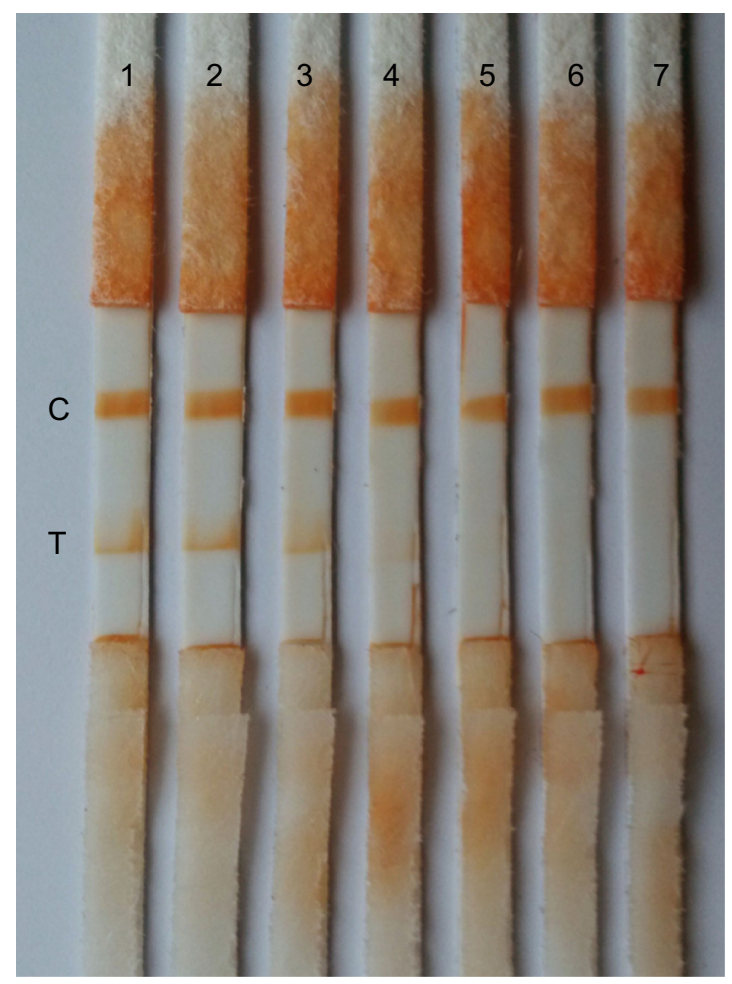

Figure 9 The stability assay of melamine test strip in milk powder after I year of storage.

Notes: I: uncontaminated milk powder; 2-7: uncontaminated milk powder spiked with melamine at concentrations of I, 5, 10,50, 100, and $500 \mu \mathrm{g} / \mathrm{L}$, respectively. Abbreviations: $\mathrm{C}$, control line; $\mathrm{T}$, test line. 


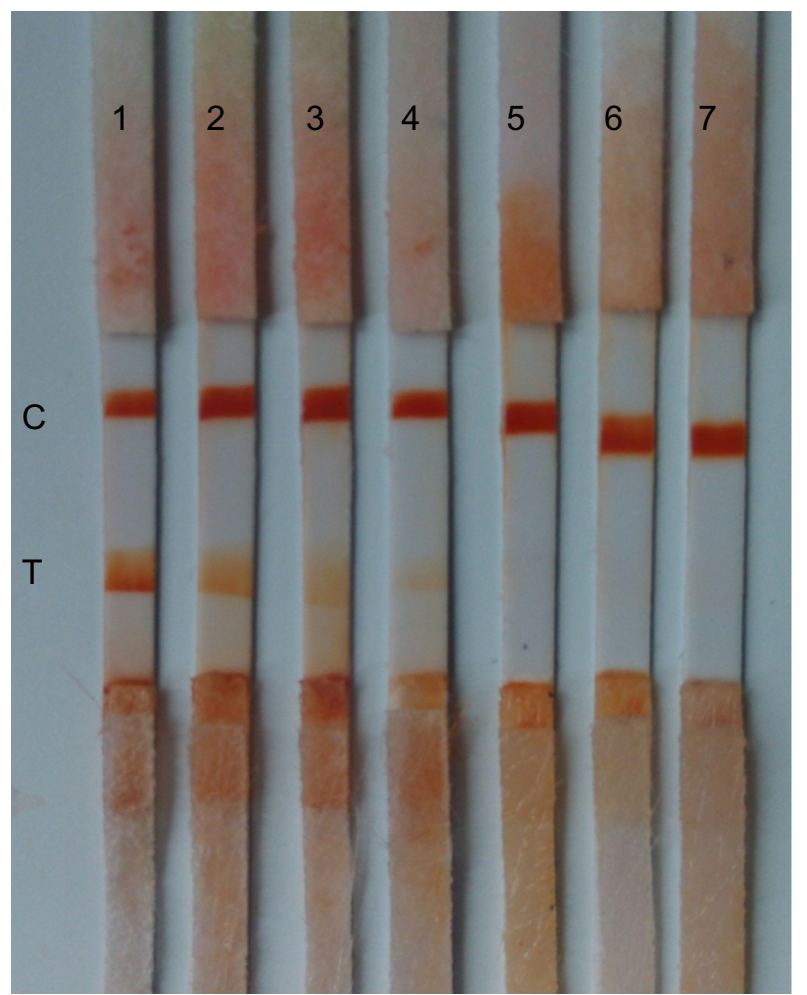

Figure 10 The stability assay of melamine test strip in animal feed after I year of storage.

Notes: I: uncontaminated animal feed; 2-7: animal feed spiked with melamine at concentrations of $10,20,50,100,200$, and $500 \mu \mathrm{g} / \mathrm{L}$, respectively.

Abbreviations: $\mathrm{C}$, control line; $\mathrm{T}$, test line.

The test strip sensitivity reached $50 \mu \mathrm{g} / \mathrm{L}$ and $100 \mu \mathrm{g} / \mathrm{L}$ when detecting MEL in milk products and animal feed, respectively, with no cross-reaction with cyanuric acid, cyanurodiamide, or ammelide. Moreover, the MEL test strip can remain stable for 1 year at RT. When the MEL strip was used in milk products, samples needed to be diluted, or else chromatography could not be performed at all. The LOD of $50 \mu \mathrm{g} / \mathrm{L}$ in milk products was determined after threefold dilution with water. Milk powder diluted with water in a proportion of $1 \mathrm{~g}$ milk powder to $20 \mathrm{~mL}$ water could be tested with the MEL strip, hence the LOD should be adjusted to $150 \mu \mathrm{g} / \mathrm{kg}$ for liquid milk, and $1,000 \mu \mathrm{g} / \mathrm{kg}$ for milk powder. The dilution fold for animal feed was eight, therefore the
LOD is adjusted to $800 \mu \mathrm{g} / \mathrm{kg}$. Liquid milk samples contaminated at $30 \mu \mathrm{g} / \mathrm{kg}$ and $150 \mu \mathrm{g} / \mathrm{kg}$ MEL were validated by LC-MS/MS. The results showed that $24.90 \mu \mathrm{g} / \mathrm{kg}$ and $141.69 \mu \mathrm{g} / \mathrm{kg}$ MEL were detected, and the relative standard deviation was less than $11.27 \%$. Considering that the levels of MEL permitted by the World Health Organization are $2,500 \mu \mathrm{g} / \mathrm{kg}$ for adult food and animal feed and $1,000 \mu \mathrm{g} / \mathrm{kg}$ for infant food, ${ }^{16}$ the LODs of the colloidal selenium test strip are sufficient to control MEL limits.

MEL contamination presents a clear and present threat to human and animal health. Although colloidal gold MEL test strips are a rapid and sensitive detection tool, the colloidal selenium MEL test strip has been proven to be a more accessible and cost-effective alternative in our present work.

Previous works have shown that the LOD of MEL by colloidal gold test strip was $0.26 \mu \mathrm{g} / \mathrm{kg}^{29}$ and $500 \mu \mathrm{g} / \mathrm{kg}$ in milk products, ${ }^{27}$ while reaching $1,000 \mu \mathrm{g} / \mathrm{kg}$ and $2,000 \mu \mathrm{g} /$ $\mathrm{kg}$ MEL in milk powder and in animal feeds, respectively. ${ }^{28}$ The remarkably different results are mainly attributed to whether samples were pretreated with organic solvent, high-speed centrifuge, and an evaporator. ${ }^{28,29}$ In contrast, samples in our present work only required dilution. Given more complex pretreatment, the LOD of the MEL colloidal selenium test strip would likely be greatly improved. In view of LOD, it could not be ascertained which method achieves greater sensitivity. Compared to colloidal gold, colloidal selenium reduced preparation cost 27 -fold (Table 1) under the same amount of labeled antibody. Taken together, the MEL based on colloidal selenium test strip is a highly specific, easy-to-prepare and operate, cost-effective, and sensitive device for the rapid and reproducible detection of MEL.

It must be noted the situation that the limitation of gray zones in test strips could not be avoided in this study either. When $60-90 \mu \mathrm{g} / \mathrm{kg}$ MEL contained in samples is close to the LOD, the test zone will be very obscure. Thus it is difficult to discriminate the test result by the naked eye. The colloidal selenium immunoassay-based test strip for MEL detection

Table I Consumption contrast of I liter colloidal gold and colloidal selenium preparation

\begin{tabular}{|c|c|c|c|c|c|}
\hline \multirow{2}{*}{$\begin{array}{l}\text { Type } \\
\text { Material }\end{array}$} & \multicolumn{2}{|c|}{ Colloidal gold } & \multicolumn{3}{|c|}{ Colloidal selenium } \\
\hline & $\mathrm{AuCl}_{4} \mathrm{H}_{9} \mathrm{O}_{4}$ & $\mathrm{C}_{6} \mathrm{H}_{9} \mathrm{Na}_{3} \mathrm{O}_{9}$ & $\mathrm{H}_{2} \mathrm{SeO}_{3}$ & Vc & GA \\
\hline Unit price (USD/g) & 50.620 & 0.010 & 0.290 & 0.049 & 0.016 \\
\hline Dosage $(\mathrm{g})$ & 0.100 & 0.100 & 0.258 & 1.404 & 2.500 \\
\hline Cost per dosage (USD) & 5.062 & 0.001 & 0.075 & 0.069 & 0.040 \\
\hline Total cost (USD) & 5.063 & & & 0.184 & \\
\hline Ratio & \multicolumn{5}{|c|}{$5.063 / 0.184=27.516$} \\
\hline
\end{tabular}

Abbreviations: $\mathrm{AuCl}_{4} \mathrm{H}_{9} \mathrm{O}_{4}$, chloroauric acid tetrahydrate; $\mathrm{C}_{6} \mathrm{H}_{9} \mathrm{Na}_{3} \mathrm{O}_{9}$, trisodium citrate dihydrate; $\mathrm{H}_{2} \mathrm{SeO}$, seleninic acid; $\mathrm{Vc}$, $\mathrm{L}$-ascorbic acid; $\mathrm{GA}$, gum arabic. 
reported herein shows potential for onsite test and in-home testing; however, other approaches would be preferable in a laboratory.

\section{Conclusion}

This study is the first to report SeNP-based lateral flow immunoassay for detection of MEL in milk and milk powder. The test strip can be prepared by simple and convenient methods and then detect MEL contamination rapidly, sensitively, and without cross-reaction with its homologues.

\section{Acknowledgments}

This work was supported by Innovation Fund for Technology Based Firms of China (No 10C26226205327). The authors are very grateful to Xuebing Wei in Gansu Food and Drug Administration, Lanzhou, the People's Republic of China, for his kind help in operating LC-MS/MS and to Dr Joshua Philip of the University of Western Sydney, Australia, for his kind language assistance.

\section{Disclosure}

The authors report no conflicts of interest in this work.

\section{References}

1. Alan AF. Final report on the safety assessment of melamineformaldehyde resin. J Am Coll Toxicol. 1995;14:373-385.

2. Yilmaz ÜT, Yazar Z. Determination of melamine by differential pulse polarography/application to milk and milk powder. Food Anal Methods. 2011;5(1):119-125.

3. Ai K, Liu Y, Lu L. Hydrogen-bonding recognition-induced color change of gold nanoparticles for visual detection of melamine in raw milk and infant formula. J Am Chem Soc. 2009;131(27):9496-9497.

4. Bhalla V, Grimm PC, Chertow GM, Pao AC. Melamine nephrotoxicity: an emerging epidemic in an era of globalization. Kidney Int. 2009;75(8): 774-779.

5. Thanasekaran P, Liu C-M, Cho J-F, Lu K-L. Melamine-promoted crystal growth of calcium oxalate monohydrate from calcium nitrate and oxalic acid. Inorg Chem Commun. 2012;17:84-87.

6. Panuwet P, Nguyen JV, Wade EL, D'Souza PE, Ryan PB, Barr DB. Quantification of melamine in human urine using cation-exchange based high performance liquid chromatography tandem mass spectrometry. J Chromatogr B Analyt Technol Biomed Life Sci. 2012;887-888: $48-54$.

7. Hau AK, Kwan TH, Li PK. Melamine toxicity and the kidney. JAm Soc Nephrol. 2009;20(2):245-250.

8. Zhang QX, Yang GY, Li JT, Li WX, Zhang B, Zhu W. Melamine induces sperm DNA damage and abnormality, but not genetic toxicity. Regul Toxicol Pharmacol. 2011;60(1):144-150.

9. Xu CF, Gao XL, Du YX, Ren ST. The rapid establishment and implications of a melamine-induced standardized bladder stone model in mice. Food Chem Toxicol. 2011;49(12):3013-3017.

10. Brown CA, Jeong KS, Poppenga RH, et al. Outbreaks of renal failure associated with melamine and cyanuric acid in dogs and cats in 2004 and 2007. J Vet Diagn Invest. 2007;19(5):525-531.

11. Chan EY, Griffiths SM, Chan CW. Public-health risks of melamine in milk products. Lancet. 2008;372(9648):1444-1445.

12. Ingelfinger JR. Melamine and the global implications of food contamination. N Engl J Med. 2008;359(26):2745-1748.
13. chinadaily.com [homepage on the Internet]. [China lowers dairy protein levels to curb melamine]. [updated July 15, 2010; cited September 9, 2013] Available from: http://www.chinadaily.com.cn/china/2010-07/15/ content_10107670.htm. Accessed February 4, 2014. Chinese.

14. dairy123.com [homepage on the Internet]. [Melamine was found in Mead Johnson, Nestle and other milk powder in USA]. [updated March 13, 2013; cited September 9, 2013]. Available from: http://www.dairy 123. com/news01/html/79-3/3246.htm. Accessed February 4, 2014. Chinese.

15. US Food and Drug Administration. FDA issues interim safety and risk assessment of melamine and melamine-related compounds in food [press release]. Silver Spring, MD: US Food and Drug Administration; 2008 [October 3; cited September 9, 2013]. Available from: http:// www.fda.gov/NewsEvents/Newsroom/PressAnnouncements/2008/ ucm116960.htm. Accessed February 4, 2014.

16. Gossner CM, Schlundt J, Ben Embarek B, et al. The melamine incident: implications for international food and feed safety. Environ Health Perspect. 2009;117(12):1803-1808.

17. Venkatasami G, Sowa JR Jr. A rapid, acetonitrile-free, HPLC method for determination of melamine in infant formula. Anal Chim Acta. 2010;665(2):227-230.

18. Goscinny S, Hanot V, Halbardier JF, Michelet JY, Van Loco J. Rapid analysis of melamine residue in milk, milk products, bakery goods and flour by ultra-performance liquid chromatography/tandem mass spectrometry: from food crisis to accreditation. Food Control. 2011;22(2):226-230.

19. Sun F, Ma W, Xu L, et al. Analytical methods and recent developments in the detection of melamine. Trac-trend Anal Chem. 2010;29(11): 1239-1249.

20. Ibáñez M, Sancho JV, Hernández F. Determination of melamine in milk-based products and other food and beverage products by ion-pair liquid chromatography-tandem mass spectrometry. Anal Chim Acta. 2009;649(1):91-97.

21. Squadrone S, Ferro GL, Marchis D, et al. Determination of melamine in feed: validation of a gas chromatography-mass spectrometry method according to 2004/882/CE regulation. Food Control. 2010;21(5): 714-718.

22. Chen Z, Yan X. Simultaneous determination of melamine and 5-hydroxymethylfurfural in milk by capillary electrophoresis with diode array detection. J Agric Food Chem. 2009;57(19):8742-8747.

23. Balabin RM, Smirnov SV. Melamine detection by mid- and nearinfrared (MIR/NIR) spectroscopy: a quick and sensitive method for dairy products analysis including liquid milk, infant formula, and milk powder. Talanta. 2011;85(1):562-568.

24. Jawaid S, Talpur FN, Sherazi ST, Nizamani SM, Khaskheli AA. Rapid detection of melamine adulteration in dairy milk by SB-ATRFourier transform infrared spectroscopy. Food Chem. 2013;141(3): 3066-3071.

25. Lachenmeier DW, Humpfer E, Fang F, et al. NMR-spectroscopy for nontargeted screening and simultaneous quantification of healthrelevant compounds in foods: the example of melamine. J Agric Food Chem. 2009;57(16):7194-7199.

26. Yin W, Liu J, Zhang T, et al. Preparation of monoclonal antibody for melamine and development of an indirect competitive ELISA for melamine detection in raw milk, milk powder, and animal feeds. J Agric Food Chem. 2010;58(14):8152-8157.

27. AccuAffinity I. AccuDipTM Melamine Test Strip User Guide (Product No AAF-11101). 2010:3.

28. Li X, Luo P, Tang S, et al. Development of an immunochromatographic strip test for rapid detection of melamine in raw milk, milk products and animal feed. J Agric Food Chem. 2011;59(11):6064-6070.

29. Le T, Yan P, Xu J, Hao Y. A novel colloidal gold-based lateral flow immunoassay for rapid simultaneous detection of cyromazine and melamine in foods of animal origin. Food Chem. 2013;138:1610-1615.

30. Russell RC, Yang H, Yost D, inventors; Abbott Laboratories, assignee. Non-metal colloidal particle immunoassay. European Patent EP 0298368. January 9, 1991. 
31. Sato NS, de Melo CS, Zerbiri LCMS, Silveira EPR, Fagundes LJ, Ueda M. Assessment of the rapid test based on an immunochromatography technique for detecting anti-Treponema pallidum antibodies. Rev Inst Med Trop Sao Paulo. 2003;45(6):319-322.

32. Mees DR, Pysto W, Tarcha PJ. Formation of selenium colloids using sodium ascorbate as the reducing agent. $J$ Colloid Interface Sci. 1995;170(1):254-260.

33. Zhang S-Y, Zhang J, Wang H-Y, Chen H-Y. Synthesis of selenium nanoparticles in the presence of polysaccharides. Mater Lett. 2004;58(21): 2590-2594.

34. Rong-Hwa S, Shiao-Shek T, Der-Jiang C, Yao-Wen H. Gold nanoparticle-based lateral flow assay for detection of staphylococcal enterotoxin B. Food Chem. 2010;118(2):462-466.

35. Gates B, Mayer B, Grossman A, Xia A. A sonochemical approach to the synthesis of crystalline selenium nanowires in solutions and on solid supports. Adv Mater. 2002;14(23):1749-1752.

36. Chiao DJ, Shyu RH, Hu CS, Chiang HY, Tang SS. Colloidal goldbased immunochromatographic assay for detection of botulinum neurotoxin type B. J Chromatogr B Analyt Technol Biomed Life Sci. 2004;809(1):37-41.

37. Li D, Wei S, Yang H, Li Y, Deng A. A sensitive immunochromatographic assay using colloidal gold-antibody probe for rapid detection of pharmaceutical indomethacin in water samples. Biosens Bioelectron. 2009;24(7):2277-2280.
38. Vallari AS, Hickman RK, Hackett JR Jr, Brennan CA, Varitek VA Jr, Devare SG. Rapid assay for simultaneous detection and differentiation of immunoglobulin $\mathrm{G}$ antibodies to human immunodeficiency virus type 1 (HIV-1) group M, HIV-1 group O, and HIV-2. J Clin Microbiol. 1998;36(12):3657-3661.

39. Zhou Y, Pan FG, Li YS, et al. Colloidal gold probe-based immunochromatographic assay for the rapid detection of brevetoxins in fishery product samples. Biosens Bioelectron. 2009;24(8):2744-2747.

40. Kolosova AY, Sibanda L, Dumoulina F, et al. Lateral-flow colloidal gold-based immunoassay for the rapid detection of deoxynivalenol with two indicator ranges. Anal Chim Acta. 2008;616(2):235-244.

41. Juntunen E, Myyryläinen T, Salminen T, Soukka T, Pettersson K. Performance of fluorescent europium(III) nanoparticles and colloidal gold reporters in lateral flow bioaffinity assay. Anal Biochem. 2012;428(1):31-38.

42. Sithigorngula P, Rukpratanporn S, Pecharaburanin N, et al. A simple and rapid immunochromatographic test strip for detection of pathogenic isolates of Vibrio harveyi. J Microbiol Methods. 2007;71(3):256-264.

43. Chandler J, Gurmin T, Robinson N. The place of gold in rapid tests. IVD Technol. 2000;6:37-49.
International Journal of Nanomedicine

\section{Publish your work in this journal}

The International Journal of Nanomedicine is an international, peerreviewed journal focusing on the application of nanotechnology in diagnostics, therapeutics, and drug delivery systems throughout the biomedical field. This journal is indexed on PubMed Central,

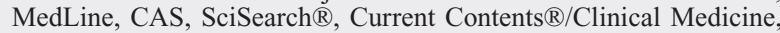

\section{Dovepress}

Journal Citation Reports/Science Edition, EMBase, Scopus and the Elsevier Bibliographic databases. The manuscript management system is completely online and includes a very quick and fair peer-review system, which is all easy to use. Visit http://www.dovepress.com/ testimonials.php to read real quotes from published authors. 